\title{
ANALYSIS OF RISKS AND OPPORTUNITIES IN THE BMW GROUP
}

https://doi.org/10.47743/jopafl-2021-22-12

\author{
Ionel - Gabriel DOBRIN \\ Drăgan European University Lugoj, \\ Lugoj, România \\ gabriel.dobrin@deu.ro
}

\begin{abstract}
According to Group-wide guidelines, every employee and manager has the duty to report risks via the relevant reporting channels. The key elements of an effective risk culture are embedded in the BMW Group's core values. Regarding the risk management system, training programmes and informational events are regularly conducted across the BMW Group. These measures are essential ways of preparing those involved in the process to comply with any new or additional requirements.
\end{abstract}

Keywords: risks, opportunities, management, impact, threats, assessment, earnings, production, technologies, sales.

\section{Introduction}

The risk management process applies across the entire BMW Group and comprises the early identification, analysis and assessment of risks, the coordinated use of appropriate management tools and the monitoring and evaluation of the measures taken. The BMW Group uses standardised methods to assess risks. All significant risks are measured using value-at-risk models and assessed on the basis of uniform loss distribution metrics, thereby enabling better comparison of risks for both internal and external reporting purposes. The overall effect of risks on the results of operations, as well as the financial assets position present a strong impact on the company's earnings. Thus, risks are classified both according to their potential impact on earnings (pessimistic scenario) as well as according to the risk amount, taking into account the probability of occurrence. The impact of risks is measured and reported net of any mitigation measures that are already taking effect (net basis). Risks in the BMW Group are usually measured over a two-year assessment period.

\section{Risk management in the BMW group}

Table 1 The potential impact on earnings in the pessimistic scenario is classified as it follows:

\begin{tabular}{|c|c|}
\hline Class & $\begin{array}{c}\text { Potential impact on earnings } \\
\text { in a pessimistic scenario }\end{array}$ \\
\hline Low & $>€ 0-500$ million \\
\hline Medium & $>€ 500-2,000$ million \\
\hline High & $>€ 2,000$ million \\
\hline
\end{tabular}

Source: www.bmwgroup.com/en.html

Table 2 The following criteria apply for the purpose of classifying the risk amount:

\begin{tabular}{|c|c|}
\hline Class & Risk amount \\
\hline Low & $>€ 0-50$ million \\
\hline
\end{tabular}




\begin{tabular}{|l|c|}
\hline Medium & $>€ 50-400$ million \\
\hline High & $>€ 400$ million \\
\hline
\end{tabular}

Source: www.bmwgroup.com/en.html

Figure 1. Risk management at BMW Group

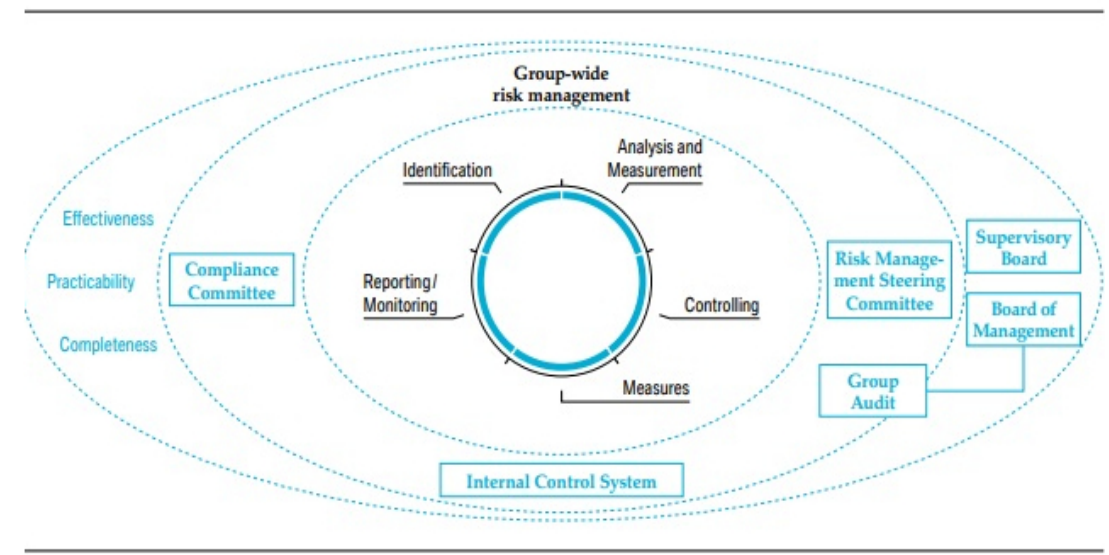

Source: www.bmwgroup.com/en.html

The impact of risks and opportunities on earnings is presented separately without offsetting. If no specific reference is made, opportunities and risks relate to the Automotive segment. The entities covered in the report on risks and opportunities corresponds to the consolidated entities included in the BMW Group Financial Statements. A dynamic market environment also gives rise to opportunities. Identifying these opportunities is an integrated part of the BMW Group’s strategic planning process. The Group's range of products and services is continually reviewed on the basis of extremely complex analyses. In order to compete successfully on the long term and at the same time effectively help play an active role in achieving the goal of climate neutrality, the BMW Group's vehicle platforms are designed to operate flexibly with various types of drivetrain, enabling it to respond more swiftly to changing customer needs. In the BMW Group, once identified, opportunities are acted upon in the relevant operational areas on a decentralised basis. The importance of opportunities for the BMW Group is classified on a qualitative basis in the categories "significant" and "insignificant". Probable measures aimed at increasing profitability are already incorporated in the outlook.

\section{Significant risks and opportunities in the BMW Group}

The following table provides an overview of significant risks and opportunities and indicates their level of importance for the company. Overall, no risks capable of threatening the continued existence of the BMW Group were identified either at the balance sheet date or at the date on which the Group Financial Statements were drawn up.

Table 3. Significant risks and opportunities in the BMW Group

\begin{tabular}{|l|c|c|c|c|}
\hline & \multicolumn{2}{|c|}{ Risks } & \multicolumn{2}{c|}{ Opportunities } \\
\hline & $\begin{array}{c}\text { Classification of risk } \\
\text { amount }\end{array}$ & $\begin{array}{c}\text { Change } \\
\text { compared to } \\
\text { prior year }\end{array}$ & $\begin{array}{c}\text { Classification } \\
\text { compared to } \\
\text { prior year }\end{array}$ \\
\hline & \multicolumn{3}{|c|}{} \\
\hline
\end{tabular}




\begin{tabular}{|c|c|c|c|c|}
\hline $\begin{array}{l}\text { Macroeconomic risks } \\
\text { and opportunities }\end{array}$ & High & Stable & Significant & Increased \\
\hline \multicolumn{5}{|l|}{$\begin{array}{l}\text { Strategic and sector } \\
\text { risks and opportunities }\end{array}$} \\
\hline $\begin{array}{l}\text { Changes in legislation and } \\
\text { regulatory requirements }\end{array}$ & High & Stable & Insignificant & Stable \\
\hline Market developments & High & Stable & Insignificant & Stable \\
\hline \multicolumn{5}{|l|}{$\begin{array}{l}\text { Risks and opportunities } \\
\text { relating to operations }\end{array}$} \\
\hline $\begin{array}{l}\text { Risks and opportunities } \\
\text { relating to production } \\
\text { and technologies }\end{array}$ & High & Stable & Insignificant & Stable \\
\hline $\begin{array}{l}\text { Risks and opportunities } \\
\text { relating to purchasing }\end{array}$ & High & Increased & Insignificant & Stable \\
\hline $\begin{array}{llr}\text { Risks and } & \text { opportunities } \\
\text { relating } & \text { to } & \text { sales } \\
\text { networks } & & \end{array}$ & High & Stable & Insignificant & Stable \\
\hline $\begin{array}{ll}\text { Information, } & \text { data } \\
\text { protection and IT }\end{array}$ & High & Stable & Insignificant & Stable \\
\hline \multicolumn{5}{|l|}{$\begin{array}{l}\text { Financial risks and } \\
\text { opportunities }\end{array}$} \\
\hline $\begin{array}{l}\text { Currency risks and } \\
\text { opportunities }\end{array}$ & High & Increased & Significant & Stable \\
\hline $\begin{array}{l}\text { Risks and opportunities } \\
\text { relating to raw materials } \\
\text { prices }\end{array}$ & Medium & Stable & Significant & Stable \\
\hline Liquidity risks & Medium & Increased & - & - \\
\hline Other financial risks & Medium & - & Significant & - \\
\hline Legal risks & Medium & Stable & - & - \\
\hline
\end{tabular}

Source: www.bmwgroup.com/en.html

\section{Macroeconomic risks and opportunities}

Economic conditions have a major impact on business performance and hence the level of earnings generated by the BMW Group. Unforeseen disruptions in global economic relations can have highly unpredictable effects. Thus, macroeconomic risks due to sales volume fluctuations could have a significant earnings impact over the two-year assessment period. Currently, the greatest risk for the global economy is the further spread and the consequences of the COVID-19 pandemic. It is not currently possible to predict with any degree of certainty the point in time from which a high vaccination rate could significantly mitigate the course of the pandemic. As a result, restrictions to public life and regional lockdowns are likely to be a continued source of uncertainty for consumers. The BMW Group is monitoring the situation on a continuous basis and taking appropriate measures as required.

Strategic and sector-specific risks and opportunities

The short-term introduction of more stringent regulations, particularly with regard to emissions, safety and consumer protection as well as regional, vehicle-related purchase and usage taxes, represents a significant risk for the automobile industry. Country-specific trade barriers can also be subject to change at short notice.

Any sudden tightening of regulations in these areas could require significantly higher investments and ongoing expenses or exert influence on customer behaviour. Market developments 
Apart from economic factors and sector-specific political conditions, increasingly fierce competition among established manufacturers and the emergence of new market competitors could also have effects that are difficult to predict. Unforeseen consumer preferences and changes in brand perceptions can also give rise to both opportunities and risks.

Risks and opportunities relating to production and technologies

Risks relating to production processes and fields of technology can lead to unplanned production interruptions or additional costs due to vehicle recalls. If any such risks were to materialise, they could have a high impact on all BMW Group's earnings over the two-year assessment period. Also, potential causes generated by production downtimes include fires, infrastructural damage, machine and tooling breakdowns, IT malfunctions, temporary disruptions in utility supply or transportation and logistical disruptions, or the outbreak of a global pandemic. The BMW Group analyses new opportunities relating to production processes and fields of technology primarily in the competitive edge gained by mastering new and complex manufacturing technologies.

Risks and opportunities relating to purchasing

Purchasing risks relate primarily to supply risks caused by the failure of a supplier to deliver as well as to threats to BMW Group-relevant know-how within the supplier network. Production problems at supplier level could lead to unfavourable consequences caused by company's increased expenditure, due to production interruptions and to a corresponding reduction in vehicle sales. The BMW Group deploys an extensive set of checks and proactive management measures to tackle the challenges currently facing the automotive supply industry.

Risks and opportunities relating to the sales network

In order to sell its products and expand its services, the BMW Group operates a global sales network mainly comprising independent dealerships, branches, subsidiaries and importers. In addition, a pilot project to promote direct sales was launched in South Africa in 2020. Any threat to the continued activities of parts of the sales network would entail risks for the BMW Group. The occurrence of sales and marketing risks would have only a low impact on earnings over the two-year assessment period of the company.

Currency risks and opportunities.

The BMW Group conducts business in a variety of currencies, thus giving rise to currency risks and opportunities. A substantial part of BMW Group revenues, purchasing and funding occur outside the eurozone, especially in China and the USA. Regularly updated cash-flow-at-risk models and scenario analyses are used to measure currency risks and opportunities. If currency risks were to materialise, they could be associated with a high impact on the earnings made over the two-year assessment period of the company. Thus, significant opportunities can arise if currency developments are favourable for the BMW Group.

Risks and opportunities relating to raw materials prices

As a large-scale manufacturing company, the BMW Group is often exposed to purchase price risks, especially in relation to the raw materials used in vehicle production. The analysis of raw materials price risks is based on planned purchases of raw materials and components. Cash-flow-at-risk models and scenario analyses are used to measure risks and opportunities relating to raw materials prices.

Liquidity risks 
The major part of the Financial Services segment's credit financing and leasing business is refinanced on capital markets. Liquidity risks can arise in the form of rising refinancing costs or from restricted access to funds as a consequence of the general market situation. If liquidity risks were to materialise, they would be likely to have a medium impact on the BMW Group earnings over the two-year assessment period.

Other financial risks

Other financial risks worth mentioning include counterparty risks as well as those arising in connection with investments in other entities. The BMW Group works together with banks to ensure that the available liquidity is optimally invested and to hedge against financial market risks (especially currency, commodity and interest rate risks) using derivative financial instruments. If other financial risks were to materialise, they could have a medium impact on earnings over the two-year assessment period. Revaluations of investments could give rise to opportunities with a significant impact on earnings. Legal risks

The BMW Group is exposed to various legal risks due to the global nature of its operations. Legal risks may result from non-compliance with laws or other legal requirements by business partners or other market participants. However, it cannot be ruled out that new legal risks, as yet unforeseen, materialise that could have a high impact on the earnings of BMW Group.

\section{Conclusions}

Threats management strategies certainly refer to avoiding them, reducing negative effect or threat probability, as well as total or partial transfer of threats. The opposite of previously mentioned strategies is used to answer to opportunities regarding uncertain conditions with benefits in the future. Otherwise, risks can occur from various sources, including: uncertainty on international markets, threats generated by failures, volatility of legal liabilities, the impact on credit risk, accidents, natural causes or disasters or the impact on some events with an uncertain or unpredictable cause. As a consequence, there are two types of events, negative events that can be classified as risks, and positive effects that can be classified as opportunities.

\section{Reference}

1. Dobrin G.I., (2013) Economics and risk assessment in the business world, "Lucian Blaga” University Publishing House, Sibiu;

2. Dobrin G.I., (2014) Analysis and evaluation of risks specific to the Romanian business environment, "Lucian Blaga” University Publishing House, Sibiu;

3. Schmidt Timeea (2014) The Importance, Necessity and Role of the Global Diagnosis of the Company in the Evaluation Process, Nagard Publishing House, Lugoj

4. www.bmwgroup.com/en.html 